\title{
CONSTITUINTES E DESAFIOS DA PROFISSIONALIZAÇÃO DE DOCENTES DE LÍNGUA INGLESA PARA A INFÂNCIA
}

\author{
CONSTITUYENTES Y LOS DESAFÍOS DE LA PROFESIONALIZACIÓN DE \\ DOCENTES DE LENGUA INGLESA PARA LA INFANCIA
}

\author{
CONSTITUENTS AND CHALLENGES OF PROFESSIONALIZATION OF ENGLISH \\ AS FOREIGN LANGUAGE TEACHERS
}

\author{
Andréa Cristina Gomes MONTEIRO ${ }^{1}$ \\ Marcia Regina Selpa HEINZLE ${ }^{2}$
}

RESUMO: Esta pesquisa objetivou analisar os constituintes da profissionalização de docentes de Língua Inglesa para a infância e elucidar os seus principais desafios. Nos procedimentos metodológicos, foram elencados dois instrumentos de geração de dados: memorial e entrevista narrativa com professores de inglês dos anos iniciais. Ressalta-se que esta é uma pesquisa qualitativa e (auto) biográfica. A partir da análise textual discursiva, destaca-se que há diversos fatores que interferem na construção da identidade profissional dos docentes. Estes são influenciados por constituintes sociais, como família, amigos, mestres, professores mais experientes e gestores, que operam tanto nas escolhas e na profissão como no fazer docente. Os desafios, por outro lado, estão relacionados à formação continuada e, principalmente, à formação inicial. Dessa forma, propõem-se reflexões curriculares a respeito da profissionalização do docente para atuar com as diferentes idades escolares.

PALAVRAS-CHAVE: Professores de língua inglesa. Infância. Profissionalização docente.

RESUMEN: Esta investigación ha buscado evaluar los constituyentes de la profesionalización de docentes de Lengua Inglesa para la infancia, y elucidar sus principales desafíos. En los procedimientos metodológicos se han elegidos dos instrumentos de generación de datos: memorial; y entrevista narrativa con maestros de inglés de los años iniciales. Se resalta que esta es una investigación cualitativa y (auto) biográfica. A partir del análisis textual discursivo se destaca que hay diversos factores que interfieren en la construcción de la identidad profesional de los docentes, y estos han sido influenciados por constituyentes sociales como: familia, amigos, sus maestros, maestros más experimentados y gestores, que operan tanto en sus elecciones para esta profesión como en el hacer docente. Y los desafíos están relacionados con la formación continuada y principalmente en la formación inicial. De esta forma se propone reflexiones curriculares sobre la profesionalización del docente para trabajar con las diferentes edades escolares.

PALABRAS-CLAVE: Maestros de lengua inglesa. Infancia. Profesionalización docente.

\footnotetext{
${ }^{1}$ Instituto Federal Catarinense (IFC), Camboriú - SC - Brasil. Professora do IFC- Camboriú. Integrante do grupo de pesquisa GEPES - FURB. ORCID: <http://orcid.org/0000-0002-9285-6783>.E-mail: jve3043@ gmail.com. ${ }^{2}$ Universidade Regional de Blumenau (FURB), Blumenau - SC - Brasil. Professora e pesquisadora do Programa de Pós-Graduação em Educação - PPGE/FURB. Líder do grupo de pesquisa GEPES - FURB. ORCID: <http://orcid.org/0000-0002-2299-8065>. E-mail: selpamarcia@gmail.com.
} 
ABSTRACT: This research aimed to analyze the professional constituents of English as foreign teachers who work with children, and clarify their main challenges. In the methodological procedures, two tool generators were established: descriptive memorial; and narrative interviews carried out by seven teachers who work teaching English to children in elementary schools. It is highlighted that this is a qualitative and (auto)biographic research. By the use of discursive textual analysis, it is enhanced that there are several factors which interfere in the construction of the professional identity of these teachers, and that they are influenced by social constituents like: family, friends, their educators, educators known for having considerable experience in teaching and managers of learning processes. These people have greatly influenced these teachers as in their choices when talking about carrier as when they act with children at school. The challenges, on the other hand, are mostly related to the formation (continued and initial), specially the initial formation. Taking this into account, it is thought that discussions about the professionalization of teachers who act with different ages at school must be rethought in the curriculum.

KEYWORDS: English as foreign language teachers. Childhood. Professionalizing teachers.

\section{Introdução}

A profissionalização docente tem sido alvo de discussões e pesquisas há mais de trinta anos, por meio do movimento de profissionalização do ensino que começou nos Estados Unidos e espalhou-se para outros países, como o Brasil, na busca pela legitimação profissional da docência e de uma cultura da identidade docente (AMBROSETTI; ALMEIDA, 2010). Em decorrência da complexidade presente na profissão docente, essa profissionalização é entendida por meio das atividades concretas dos professores, dos contextos de trabalho e do cotidiano escolar, o que leva à percepção dela como construção social (AMBROSETTI; ALMEIDA, 2010). Dessa forma, a profissionalização docente está em constante evolução, pois a sociedade se esculpe de forma diferenciada a cada dia.

Vale ressaltar que a profissionalização não é construída somente pela participação em um curso superior, pois “vincula-se à compreensão de que tornar-se professor é um processo que se dá ao longo da vida, nos espaços de formação e na trajetória profissional, de modo a integrar elementos pessoais e sociais" (AMBROSETTI; ALMEIDA, 2010, p. 187). Nesse sentido, enfatiza-se que a profissionalização docente não se baseia somente na aquisição de conhecimentos científicos e práticos advindos da formação inicial e continuada, mas da relação entre ensino e pesquisa, questões pedagógicas no âmbito do ensino dos conteúdos específicos e da união entre teoria e prática (ARAÚJO, 2011). Como consequência dos fatores apontados, os docentes conseguem refletir, na prática, as situações únicas que acontecem em seu cotidiano na escola, bem como justificar os seus atos de forma científica e com autonomia. Sob essa perspectiva, o professor é o profissional que se coloca em constante reafirmação de seus 
conhecimentos e práticas, pois se espera dele a reelaboração permanente dos saberes, mantendo-os atualizados.

Consequentemente, para aperfeiçoar conhecimentos tão diversos, o docente participa de processos que o profissionalizam, de modo a validar e ampliar os seus horizontes. Esses processos incluem a construção da identidade docente, as influências e escolhas, tanto pela profissão como pela continuidade no trabalho como professor, e a constante busca por saberes que se dá tanto na formação continuada como na reflexividade da prática no cotidiano escolar e na pesquisa.

Partindo desse pressuposto e considerando que as propostas curriculares de formação de professores de língua inglesa (LI) nem sempre trazem como objeto a infância, este estudo questiona: como se constitui a profissionalização de docentes de LI para o trabalho com a infância? Em detrimento disso, este estudo se propõe a analisar os constituintes da profissionalização do docente de LI para o trabalho com a infância e elucidar os principais desafios a partir das trajetórias de professores de LI que atuam em escolas municipais ${ }^{3}$ com o ensino de LI para crianças. Dessa forma, nesse contexto investigativo, apresenta-se primeiramente o percurso metodológico deste estudo, posteriormente os constituintes e desafios da profissionalização de docentes de LI que trabalham com crianças em escolas municipais de uma cidade ao norte de Santa Catarina, e por último algumas considerações acerca da pesquisa.

\section{Percurso metodológico}

Este estudo ocorreu com docentes de escolas municipais de uma cidade ao norte do estado de Santa Catarina, onde o ensino de LI inicia no terceiro ano do Ensino Fundamental. Para identificar os sujeitos que fariam parte desta pesquisa, contatou-se a Secretaria de Educação do município e, por meio dela, adquiriu-se uma lista de professores concursados e habilitados para o ensino de LI em todas as escolas da Rede Municipal de Ensino. Com essa lista, foi possível identificar o total de 12 professores que atuavam em escolas públicas que possuíam somente os anos iniciais. Foram selecionados esses sujeitos pois eles trabalham em escolas que possuem somente o ensino para crianças. Contudo, como alguns desses profissionais não dispunham de tempo para participar da pesquisa, devido à carga horária de trabalho que possuíam, somente sete docentes aceitaram participar deste estudo. Considerando

${ }^{3}$ Legalmente no Brasil o ensino da LI é obrigatório a partir do $6^{\circ}$ ano do Ensino Fundamental, mas há a oferta de LI nos anos iniciais das escolas particulares e em algumas escolas municipais brasileiras. 
os princípios éticos da pesquisa ${ }^{4}$, o nome da Rede de Ensino e os nomes dos sete professores foram preservados.

Nesta pesquisa, por investigar o processo de formação do profissional professor que leciona aulas de LI para os anos iniciais, optou-se pela abordagem qualitativa do problema. Sabe-se que nesse tipo de pesquisa estudam-se fatos a partir dos significados que as pessoas atribuem a certos momentos da vida, buscando o sentido ou a interpretação dos fenômenos estudados (BARREIRO, 2014).

Quanto aos procedimentos, este estudo se classifica como (auto) biográfico. Segundo estudos de Abrahão (2004) a pesquisa (auto) biográfica permite a compreensão de um fenômeno e não as generalizações advindas da estatística, entendimento de como os sujeitos se sentem e a percepção que esses sujeitos têm do construto histórico de si e de suas aprendizagens.

Para que pudessem ser gerados e analisados os dados deste estudo, foram utilizados dois instrumentos com os sete sujeitos: 1) memorial (CUNHA, 2014); e, 2) entrevista narrativa (BAUER; GASKELL, 2002). O uso dos memoriais como ferramenta de geração de dados foi utilizado na expectativa de os docentes abordarem diversos aspectos de suas vidas, considerando fatos e pessoas que foram importantes para as suas profissionalizações para o trabalho com a infância. Sabe-se que muitas são as fontes sociais de aquisição dos saberes dos professores, portanto também são diversos os processos pelos quais os docentes se profissionalizam. Para o desenvolvimento dos memoriais, comunicou-se aos sujeitos que poderiam escrever livremente sobre a constituição deles enquanto docentes de LI para a infância. Entretanto, como os sujeitos dispunham de pouco tempo semanalmente para a escrita de memoriais, acrescentou-se mais um instrumento de geração de dados, de forma que se pudesse aprofundar a história de vida relatada nos breves memoriais. Dessa forma, a entrevista narrativa permitiu aos entrevistados uma performance mais atuante no relato de suas memórias. $\mathrm{Na}$ entrevista narrativa, “o pressuposto subjacente é que a perspectiva do entrevistado se revela melhor nas histórias onde o informante está usando sua própria linguagem espontânea na narração dos acontecimentos.” (BAUER; GASKELL, 2002, p. 95-96).

Os dados gerados (memorial e entrevistas narrativas) foram analisados por meio da Análise Textual Discursiva (ATD).

A Análise Textual Discursiva [...] pode ser descrita como um processo emergente de compreensão, que se inicia com um movimento de desconstrução, em que os textos do corpus são fragmentados e

${ }^{4}$ O projeto de pesquisa foi submetido ao Comitê de Ética em Pesquisa através da Plataforma Brasil. Nessa plataforma se encontra o parecer consubstanciado do projeto sob o número 1.456 .996 e o Certificado de Apresentação para Apreciação Ética (CAAE) com o número 53864116.6.0000.5370. 
desorganizados, seguindo-se um processo intuitivo auto-organizado de reconstrução com emergência de novas compreensões que, então, necessitam ser comunicadas e validadas cada vez com maior clareza em forma de produções escritas. (MORAES; GALIAZZI, 2016, p. 63).

Essa metodologia de análise oferece ao pesquisador a possibilidade de maior intimidade com os dados obtidos por meio dos instrumentos de geração de dados, os quais para os autores supracitados tratam-se de um corpus. Neste estudo, esse corpus é composto pelos dados gerados através da escrita dos memoriais que foram desenvolvidos pelos professores e também das transcrições das entrevistas narrativas que foram realizadas com os professores sujeitos deste estudo.

A partir do intenso manuseio do corpus deste estudo sob a ótica da profissionalização docente, emergiram as unidades de análise desta pesquisa que posteriormente puderam ser categorizadas. "É com base nela [categorização das unidades de análise] que se constrói a estrutura de compreensão e de explicação dos fenômenos investigados." (MORAES; GALIAZZI, 2016, p. 138). Os autores ressaltam ainda que pela classificação dessas unidades de análise resultam as categorias que neste estudo são classificadas como emergentes.

Por se tratar de categorias emergentes, “[...] o pesquisador assume uma atitude fenomenológica de deixar que os fenômenos se manifestem, construindo suas categorias a partir das múltiplas vozes emergentes nos textos que analisa.” (MORAES; GALIAZZI, 2016, p. 139). Essas categorias foram definidas a posteriori, tendo em vista que os dados desta pesquisa trabalham com a construção de histórias de vidas.

Quadro 01 - Unidades e Categorias

\begin{tabular}{|l|l|}
\hline \multicolumn{1}{|c|}{ UNIDADES } & \multicolumn{1}{c|}{ CATEGORIAS } \\
\hline Identidade Docente & a. Formação; \\
& b. Atuação. \\
\hline \multirow{3}{*}{ Constituintes sociais } & a. Influências da família e outros sujeitos; \\
& b. Influências provenientes dos mestres; \\
& c. Influências dos professores mais experientes; \\
& d. Influências dos gestores. \\
\hline \multirow{3}{*}{ Desenvolvimento } & a. A escolha pelo trabalho com a infância; \\
profissional docente & b. Busca de saberes; \\
& c. Experimentos da prática; \\
& d. Formação continuada; \\
\hline
\end{tabular}

Fonte: Autoria própria (2017)

Segundo Moraes e Galiazzi (2016), a última etapa da análise que nos leva à compreensão dos fenômenos se dá através da construção de um metatexto que somente pode 
ser elaborado após um estudo em espiral de todo o corpus da pesquisa. Este estudo em espiral permite que a cada nova rodada de análises novos pontos de vista possam ser vislumbrados pelo pesquisador. Com essa compreensão, foram analisados os excertos a partir dos aportes teóricos que sustentam conceitos sobre o processo de profissionalização docente, de forma a observar o fenômeno da profissionalização dos docentes que participaram deste estudo.

\section{Constituintes e desafios da profissionalização}

Partimos inicialmente do pressuposto que se profissionalizar, enquanto docente, está para além da formação inicial ou continuada, embora esses processos formativos façam parte da profissionalização docente. Dessa forma, para analisar os constituintes do processo de profissionalização dos docentes deste estudo, faz-se necessário observar aspectos voltados aos seus contextos de trabalho, suas atividades concretas enquanto docentes, e suas trajetórias profissionais e pessoais.

A partir da análise dos dados, compreende-se que o coletivo de docentes desta pesquisa, passou por alguns processos e aspectos que os profissionalizaram para o trabalho com a infância. Entre eles: as construções de identidades, as influências sociais (família, amigos, mestres, professores mais experientes e gestores) e aspectos do desenvolvimento profissional (emoções, reflexividade, autonomia, pesquisa, prática, formações e desafios).

No que se refere à construção da identidade, a primeira questão a ser pontuada está no campo de atuação desses profissionais, pois, embora tenham habilitação para o trabalho com a Língua Portuguesa e a LI, escolheram atuar essencialmente com o ensino da LI. Os docentes também ressaltam que sua formação inicial foi direcionada para a atuação nos anos finais do Ensino Fundamental e Médio, mas que no decorrer do seu percurso profissional optaram por trabalhar com a infância. Essas duas escolhas feitas pelos docentes demonstram o interesse que eles possuem pela área na qual atuam e a identificação que têm em relação à faixa-etária com a qual trabalham.

A partir da análise das narrativas dos sujeitos também fica aparente que suas escolhas profissionais e práticas pedagógicas em sala de aula estão repletas de suas histórias de vida e da forte relação com o 'outro'. Nesse sentido, quando relatam sobre as suas características em ser professor para a infância, os docentes declaram:

[A] forma de falar, sempre explicando tudo com muita calma e clareza. (MEMORIAL P2) 
[Que] como professora faço o mesmo para atrair o interesse dos meus alunos. [...] Apesar de às vezes não demonstrar muito carinho (abraçar, alisar, beijar) estou sempre presente quando sinto que os alunos precisam de mim. (MEMORIAL P3)

[A] persistência em tentar ver o melhor da situação, em não desistir mesmo quando está muito difícil. (MEMORIAL P5)

[Que] nunca havia pensado em ser professora das séries iniciais, nem professora eu não pensava. [...]Então eu comecei, começou um grupo muito bom. A gente fez amizade e eu acabei gostando. (ENTREVISTA P6)

Esse 'outro', presente nas características ${ }^{5}$ do ser professor, é visível no destaque à responsabilidade no processo de ensino e aprendizagem e reside na preocupação que a P2 possui em relação à forma de como se expressar com seus alunos; fica aparente nos dizeres da P3 quando ela se preocupa em ofertar uma aula de qualidade e demonstra o sentimento de carinho e cuidado para com os alunos; habita as relações conflituosas que a P5 alega enfrentar quando dos desafios nos processos de ensinar e aprender; também está no acolhimento feito pelo grupo de professores com o qual atuava a P6. Assim, percebe-se que as relações que os professores estabelecem com as outras pessoas no contexto escolar estão impregnadas de relações pessoais estabelecidas pelo docente e fundidas no seu ser pessoa e professor. Isso quer dizer que o seu ser professor é indissociável do seu eu pessoal.

Ao analisar as influências sociais que contribuíram na profissionalização dos docentes de LI para o trabalho com a infância, constata-se que a experiência vivenciada por cada um dos sujeitos da pesquisa é única, bem como todo o seu processo de formação para a docência. Contudo, existem influências que se assemelham nesses processos: a influência da família, professores que os formaram desde a educação infantil até a licenciatura, os professores mais experientes da escola e os gestores.

Entre as principais influências narradas pelos docentes está a interação com familiares. Nesse ponto, os pesquisados trazem pequenos detalhes, os quais remetem à escolha profissional.

Via na minha tia professora uma referência, pois passava as férias a observando arrumar o material dela, os cadernos de planejamento na bolsa de palha. [...] Isso de alguma maneira me influenciou a seguir minha trajetória profissional como docente para a infância. (MEMORIAL P3).

De acordo com Tardif (2012), as pessoas também podem ser induzidas pelo habitus familiar, quando alguém de relação próxima possui tarefas ligadas ao ensino, estabelecendo

${ }^{5}$ As características do ser professor para a infância foram descritas pelos docentes na escrita do memorial. 
uma relação de afeto e proximidade com a profissão. Assim, entende-se que o processo de escolha profissional não ocorre em terreno neutro, mas em meio a uma intensa mistura de vozes e atores sociais. Percebe-se, nesta análise, que essas vozes também permeiam o atuar do docente, pois "o saber dos professores é profundamente social e é, ao mesmo tempo, o saber dos atores individuais que o possuem e o incorporam a sua prática profissional para a ela adaptálo e para transformá-lo" (TARDIF, 2012, p. 15). Nesse sentido, identifica-se, nas narrativas e nos memoriais dos professores, essa mescla de saberes e práticas docentes oriundos das influências que os diversos contextos trazem aos profissionais docentes.

É interessante observar que as lembranças de práticas docentes negativas também são mencionadas pelos professores deste estudo.

Não passo textos para traduzir e eles ficam felizes da vida, porque eu tenho trauma da época em que eu estudava [...]. Então o que eu sinto que foi ruim pra mim, eu acredito que será ruim pra eles também. (ENTREVISTA P2)

Sob essa perspectiva, Tardif (2012) aponta que os professores julgam a partir do que vivenciaram em sua história de vida como estudantes: se algo foi negativo para eles, também será pouco proveitoso para os seus alunos. Metodologias aplicadas com esses docentes em período escolar podem ser replicadas ou não, dependendo da percepção de eficiência que o docente teve em relação ao método vivenciado. "Ou seja, os modelos com os quais o futuro professor ou professora aprende perpetuam-se com o exercício de sua profissão docente, já que esses modelos se convertem, até de maneira involuntária, em pauta de sua atuação." (IMBERNÓN, 2011, p. 65). A resistência em usar a tradução de textos em LI nas aulas da P2 demarca, portanto, o embate com um modelo de ensino experimentado e considerado pouco eficiente por ela.

Os docentes deste trabalho também revelam que os professores mais experientes foram essenciais nos primeiros anos de sua atuação, contribuindo com experiências práticas que poderiam ser replicadas pelos sujeitos do estudo. Destacam que esses professores mais experientes foram auxiliando na validação de métodos e atividades que os docentes deste estudo propunham.

A troca de experiências sempre foi e ainda é uma das coisas mais importantes. Dava muita vergonha de falar o que eu fazia em sala, pois eu era novato e ainda não sabia se o que eu fazia era importante ou não. (MEMORIAL P1)

A insegurança presente nas primeiras manifestações do docente frente ao grupo de professores mais experientes é comum em professores que estão transitando da identidade de 
licenciando para professor. Esse sentimento é vencido na acolhida dos outros profissionais e na sensação de pertencimento que é adquirida ao longo da profissão.

Os sujeitos deste estudo também apontam para outro profissional, que contribui para o desenvolvimento da profissionalização de docentes de LI para a infância: os professores regentes das turmas dos anos iniciais. Os professores regentes, segundo os dados da pesquisa, trabalham em parceria com os docentes de LI, principalmente, quando se trata de entender as características do comportamento dos discentes. Isso ocorre em razão dos professores regentes passarem mais tempo com a turma e, portanto, conhecerem melhor os discentes, enquanto os docentes de LI, devido às suas condições de trabalho, têm somente uma aula semanal com cada turma, fator que dificulta o conhecimento da especificidade de cada estudante.

Ah, eu sempre converso porque a gente está muito junto, então eu sempre pergunto [...] Mais a questão de conhecimento dos alunos, porque eles têm mais tempo com ela, então eu quero saber pra conhecer eles e chegar mais próximo deles. (ENTREVISTA P3)

As experiências dos professores regentes das turmas dos anos iniciais influenciam diretamente no trabalho dos docentes de LI que muitas vezes ingressaram na carreira sem experiências relacionadas ao processo de alfabetização. Dessa forma, os professores regentes auxiliam não somente no conhecer as individualidades de cada aluno, mas também na execução de tarefas adequadas à faixa etária a qual se está trabalhando.

Também se percebe, com base nos dados desta pesquisa, que a condução oferecida pelos gestores (supervisores, orientadores e diretores) exerce influência nas ações desenvolvidas em sala de aula pelos docentes. Segundo os professores P1, P2, P3, P6 e P7, uma supervisora de LI da Rede Municipal de Ensino foi essencial na superação da experiência inicial em sala de aula, principalmente em relação ao trabalho com uma faixa etária para a qual eles nunca haviam lecionado.

Foi ela quem primeiramente me abriu os olhos para caminhos nunca vistos. Os caminhos das crianças de terceiro ao quinto ano. Do lúdico. (MEMORIAL P1).

Por meio desse relato, foi possível perceber o significativo papel do supervisor como parceiro no processo de profissionalização docente, especialmente quando o gestor acompanha os anseios e os desafios vivenciados pelos docentes em seu dia a dia na escola. Um supervisor especializado na área de LI proporcionou a estes docentes maior segurança na atuação com o ensino da LI nos anos iniciais. 
Ao discutir o desenvolvimento profissional do docente de LI, constatam-se as razões das suas escolhas em atuar nos anos iniciais. Nos excertos dos sujeitos deste estudo, figura-se que os professores P1, P2, P3, P4 e P6 não fizeram a opção pelo trabalho com a infância logo quando ingressaram como professores nas escolas. Contudo, após as primeiras experiências com as crianças, esses profissionais se afeiçoaram ao ensino para essa faixa etária e decidiram continuar a trabalhar com as crianças, chegando a descartar o trabalho com outras idades. Dentre os fatores apontados para essa decisão, estão: a espontaneidade da criança e a facilidade em abordar os temas que são propostos para lecionar nos anos iniciais. Os professores destacaram também a importância da curiosidade que as crianças têm e a receptividade dos alunos em relação à disciplina que contribui para suas motivações profissionais.

[...] receptividade deles, o amor que eles têm com a gente, ansiedade que eles têm com relação à aula, o carinho. [...] faz com que nos contagie e com que a gente tenha vontade de vir, de dar aulas para eles. (ENTREVISTA P6)

Esse carinho expresso pelos alunos faz o professor sentir-se acolhido no ambiente de trabalho. De acordo com Arroyo (2011), existem certas características de uma imagem de professor dos anos iniciais que ainda é difundida na sociedade: o carinho, o cuidado e a dedicação. Essas características, embora não sejam preponderantes na profissionalização da carreira docente, estão presentes no imaginário dos professores desta pesquisa e, este se torna também um dos motivos pelos quais não trocam lecionar LI para os anos iniciais por lecionar para outras faixas etárias.

Outro processo de desenvolvimento docente apontado pelos sujeitos refere-se à busca por saberes da prática docente. Nota-se, a partir da análise dos excertos, que eles estão em constante investigação, principalmente em relação a atividades e metodologias a serem desenvolvidas com as crianças em sala de aula.

[...] e continuo lendo tudo o que aparece sobre o ensino de inglês, na internet principalmente. Muito do que aplico é fruto da minha pesquisa constante de novas técnicas, materiais, sites e relatos de outros professores. (MEMORIAL P3)

Sob essa perspectiva, eles revisitam o seu fazer docente e o remodelam a partir de achados que fazem, principalmente por meio de materiais disponibilizados na internet. Essa ferramenta é amplamente utilizada pelos professores deste estudo pelo fácil acesso que os professores têm em manuseá-la, tanto no ambiente escolar como em outros espaços que frequentam. 
Contudo, para se tornar um professor reflexivo e autônomo, é elementar que os docentes tenham clareza das condições sociais que permeiam o seu fazer docente e que impactam no seu agir em sala de aula. Segundo Zeichner (2008, p. 542), um dos pontos de insucesso do desenvolvimento dos docentes reside no "[...] foco interiorizado das reflexões dos professores sobre o seu próprio ensino e sobre os estudantes, desconsiderando-se as condições sociais da educação escolar que tanto influenciam o trabalho docente em sala de aula". Os apontamentos feitos por Zeichner (2008) vêm ao encontro de falas dos professores desta pesquisa, pois os docentes apresentaram-se conscientes das realidades sociais que os circundam e que refletem em seu trabalho. Ao tomarem consciência dessas realidades, eles decidem como fazer da prática docente uma ferramenta de mudança social. Essas ações reflexivas podem ser vistas quando: percebem a existência de diversos contextos escolares; percebem que precisam contribuir na formação da cidadania e conhecimentos gerais; identificam as necessidades da comunidade; e entendem que é necessário respeitar a individualidade de contextos de cada escola, cada turma e cada aluno. Os docentes, ao refletirem as realidades com as quais atuam, tornam-se agentes sociais que, por consequência, também contribuem para a formação de novos atores sociais.

Além dos processos de desenvolvimento docente, a prática pedagógica no ciclo da infância é destacada nessa pesquisa, como um dos constituintes da profissionalização docente. Esse aspecto foi amplamente comentado e citado, tanto nas entrevistas como nos memoriais de todos os professores.

Aquela coisa de tu preparares uma aula para um quinto ano. Você chega, aplica aquela aula vê que não funcionou no quinto ano A então quando você vai para o quinto $B$ você já faz algo diferente. Depois vai para o planejamento e reformula aquele planejamento. (ENTREVISTA P1).

Nesse excerto, é visível que o P1 está em constante validação do seu fazer docente, por meio da reflexão do seu trabalho cotidiano. Percebe-se que no dia a dia em sala de aula o professor avalia suas atividades propostas: se são coerentes, se há necessidade de modificações e, quando necessária, reconstrói o seu planejamento. Portanto, verifica-se que "o saber dos professores depende, por um lado, das condições concretas nas quais o trabalho deles se realiza e, por outro, da personalidade e da experiência profissional dos próprios professores" (TARDIF, 2012, p. 16). O uso da tentativa e do erro, para os docentes deste estudo, foi praticado para compreender se os conhecimentos aprendidos a partir das experiências escolares anteriores, dos gestores, dos professores mais experientes ou mesmo dos conhecimentos adquiridos na formação inicial eram passíveis de serem empregados no ensino de LI para crianças. Nesse contexto de experiências, o aluno é apontado como importante protagonista na validação dos 
conhecimentos dos professores. As crianças são as primeiras avaliadoras das atividades propostas pelos professores e as primeiras a se manifestarem quanto à funcionalidade do ato pedagógico. Sendo assim, elas se tornam corresponsáveis pela profissionalização dos seus próprios professores.

Para além dos constituintes acima citados, ainda notam-se desafios e dificuldades no fazer docente, entre eles, as condições de trabalho nas escolas, como falta de livros didáticos, e outros materiais tecnológicos que poderiam auxiliar no processo de ensino e aprendizagem; dificuldades em ministrar aulas para alunos não alfabetizados; a falta de valorização docente, às quais se soma o fato de que a disciplina lecionada é facultativa no território brasileiro e que há pouco respaldo dos órgãos competentes no que se refere ao ensino de uma língua estrangeira. Outro aspecto ainda mencionado é a falta de diretrizes curriculares para os anos iniciais, ficando, muitas vezes, a encargo do professor decidir quais conhecimentos e com qual profundidade serão abordados os conteúdos da área.

Já a formação, relatada em duas modalidades distintas: a formação inicial (licenciatura) e a formação continuada (ofertada principalmente pela Secretaria de Educação), é apresentada pelos docentes deste estudo tanto como um dos constituintes para a profissionalização de sua atuação com a infância como quanto um dos desafios para a docência. Em relação a este tópico, os docentes reforçam a importância da formação continuada ofertada pela Secretaria de Educação para a renovação de suas práticas em sala de aula com as crianças.

As reuniões de professores de língua inglesa eram e ainda são um momento de aprendizado, trocamos muitas figurinhas. [...] Então eu não posso te dizer uma formação em específico, mas toda formação tem alguma ideia nova que você vai acabar trazendo para sala de aula ou até adaptando. (ENTREVISTA P1)

É no debate com os colegas de profissão e na troca de ideias que renovam os seus fazeres pedagógicos e se percebem parte de um coletivo de professores de LI. A possibilidade de troca de experiências entre os docentes aumenta o repertório de práticas que os professores possuem, além de contribuir para o fortalecimento de uma identidade de grupo (NÓVOA, 2009). Contudo, os professores deste estudo alegam que gostariam de ter mais momentos de discussão sobre o ensino da LI nos anos iniciais. Isso demonstra que os docentes possuem muita vontade de participar de momentos em que possam se desenvolver profissionalmente, mas que faltam temas específicos para o debate (como a docência da LI para as crianças) e a liberação para a participação nas formações quando elas ocorrem. 
Entende-se que é essencial a organização da formação continuada prevista no cronograma para atender uma Política de Formação e assim garantir a possibilidade de participação efetiva dos professores nas formações. Dessa forma seria possível colocar em prática a meta 15 do Plano Municipal de Educação (MUNICÍPIO, 2015), que prevê uma formação continuada, ofertada pelo próprio município, para o desenvolvimento profissional dos docentes.

Todavia, em relação à formação inicial, o que se percebe é que os professores deste estudo não a consideram como uma das instâncias mais importantes no que se refere às suas formações para o trabalho com crianças. Segundo esses docentes, isso pode ter sido decorrente da pouca discussão da área pretendida (LI) ou das poucas discussões das especificidades da infância. Contudo, se observados os seus relatos, perceber-se-á que existem resquícios da formação inicial em seus fazeres docentes, seja pela imitação de professores, pela discussão de disciplinas pedagógicas ou pela prática do estágio.

Tirando os professores bons que tu tens. [...] Eles falam de um mundo ideal ali na faculdade. É uma utopia, porque na realidade quando tu vais pro estágio, tu vês que aquilo ali não é... aí tu começas a recordar do teu tempo [...]. (ENTREVISTA P3)

Nota-se, portanto, a partir das vozes dos sujeitos desta pesquisa que a formação inicial contribuiu parcialmente para a construção de suas identidades docentes e seu desenvolvimento profissional, embora mencionem a lacuna em sua formação em relação ao trabalho com a infância.

\section{Considerações finais}

A partir da presente pesquisa, entende-se que a construção do ser professor permeia diferentes relações estabelecidas ao longo da vida e diversas esferas nas quais se circula. Diante disso, escolhas e ações profissionais estão pautadas nas experiências adquiridas antes e durante a formação inicial ou mesmo após o ingresso na profissão. Assim, o processo de profissionalização, construção da identidade e desenvolvimento profissional não é estático, está em constante movimento devido às experiências profissionais e pessoais que continuam a existir na vida dos docentes. Nessa perspectiva, tornar-se docente implica na junção de um grande mosaico de processos de socialização, primárias (família e escola) e secundárias (trabalho), que contribuem na individualidade do ser. Nenhum docente é igual ao outro, suas 
influências e histórias de vida são diferentes, o que acarreta na singularidade do atuar desse profissional.

Além disso, neste estudo foi possível deslumbrar que é preciso uma reconfiguração do currículo das licenciaturas em Letras, sob pelo menos quatro aspectos: 1) maior aproximação dos estudantes das realidades escolares, como a exemplo das ações que acontecem no Programa Institucional de Bolsa de Iniciação à Docência (Pibid); 2) uma formação voltada para a infância, a adolescência e a juventude; 3 ) a práxis educativa, uma constante relação entre a teoria e prática do profissional docente; 4) mobilidade e flexibilização dos currículos entre as licenciaturas.

Todavia, entende-se, a partir do relato dos professores, que a formação inicial não é a única responsável pela formação de professores. De acordo com o corpus deste estudo, compreende-se que a docência foi constituída a partir dos sujeitos sociais, das trocas de ideias com os mais experientes, com seus pares, com gestores, com as suas buscas individuais, ou mesmo na contribuição de familiares e amigos.

\section{REFERÊNCIAS}

ABRAHÃO, Maria Helena Menna Barreto. A Aventura (auto) biográfica: teoria e empiria. Porto Alegre: EDIPUCRS, 2004.

AMBROSETTI, Neusa Banhara.; ALMEIDA, Patrícia Albieri de. A constituição da profissionalidade e professores de educação infantil. In: CORDEIRO, Aliciene Fusca Machado.; HOBOLD, Márcia Souza.; AGUIAR, Maria Aparecida Lapa de (Org.). Trabalho docente: formação, práticas e pesquisa. Joinville: Editora Univille, 2010. p. 187-205.

ARAÚJO, Cristina Carvalho de. Formação continuada no cotidiano dos(as) professores (as) dos anos iniciais: desafios e possibilidades. 2011. 142f. Dissertação (mestrado em Educação). Universidade Federal do Amazonas, Manaus, 2011.

ARROYO, Miguel Gonzáles. Oficio de mestre: imagens e auto-imagens. 13. ed. RJ: Vozes, 2011.

BARREIRO, Cristhianny Bento. Pesquisas narrativas, biográficas e autobiográficas: investigando conceitos nas pesquisas do V CIPA. In: ABRAHÃO, Maria elena Menna Barreto.; BRAGANÇA, Inês Ferreira de Souza.; ARAÚJO, Mairce da Silva (Org). Pesquisa (Auto) biográfica, fontes e questões. 1. ed. Curitiba: CRV, 2014. p.129-143.

BAUER, Martin.; GASKELL, George. Tradução de Pedrinho A. Guareschi. Pesquisa qualitativa com texto: imagem e som: um manual prático. Petrópolis, RJ: Vozes, 2002. Título original: Qualitative Researching with Text, Image and Sound: a Practical Handbook.

CUNHA, Renata Cristina da. Narrativas autobiográficas de professores iniciantes no ensino superior: trajetórias formativas de docentes do curso de Letras-Inglês. 2014. 302 f. 
Tese (Doutorado em Educação) - Centro de Educação e Ciências Humanas, Universidade Federal de São Carlos. São Carlos, 2014.

IMBERNÒN, Francisco. Formação docente e profissional: formar-se para a mudança e a incerteza. Tradução de Silvana Cobucci Leite. 9. ed. São Paulo: Cortez, 2011. Título original: Formarse para el cambio y la incertidumbre. (Coleção questões da nossa época, v.14).

MORAES, Roque.; GALIAZZI, Maria do Carmo. Análise Textual Discursiva. 3.ed. rev. e ampl. Ijuí: Editora Unijuí, 2016.

MUNICÍPIO DE JOINVILLE. Constituição (2015). Lei nº 8043, de 02 de setembro de 2015. Aprova O Plano Municipal de Educacão - PME e dá outras providências. p. 01-22. Disponível em: https://leismunicipais.com.br/plano-municipal-de-educacao-joinville-sc . Acesso em: 03 jan. 2017.

NÓVOA, António. Para uma formação de professores construída dentro da profissão. In: Professores: Imagens do futuro presente. Lisboa: Educa, 2009, p. 25-46.

TARDIF, Maurice. Saberes docentes e formação profissional. 14. ed. RJ: Vozes, 2012.

ZEICHNER, Kenneth. Uma Análise Crítica Sobre a "Reflexão" Como Conceito Estruturante na Formação Docente. Educação \& Sociedade, Campinas, v. 29, n. 103, p. 535-554, ago. 2008. Quadrimestral. Disponível em: http://www.scielo.br/pdf/es/v29n103/12.pdf. Acesso em: 06 abr. 2016.

\section{Como referenciar este artigo}

MONTEIRO, Andréa Cristina Gomes; HEINZLE, Marcia Regina Selpa. Constituintes e desafios da profissionalização de docentes de língua inglesa para a infância. Revista IberoAmericana de Estudos em Educação, Araraquara, v. 14, n. 2, p. 586-600, abr./jun., 2019. EISSN: 1982-5587. DOI: 10.21723/riaee.v14i2.11133

Submetido em: 28/02/2018

Revisões requeridas: 10/05/2018

Aprovado em: 20/08/2018 